\title{
Appropriateness of Radiology Test Requests by an Emergency Department: A Retrospective Study
}

\section{Adequação dos Exames de Radiologia Solicitados por um Departamento de Emergência: Um Estudo Retrospetivo}

\author{
Rute MARTINS $\square^{1,2}$, Pedro RAIMUNDO ${ }^{3}$, Pedro ALVES ${ }^{1,2}$, Rodrigo MONTEIRO ${ }^{1,2}$, Luís Duarte SILVA ${ }^{1,2}$, \\ André GOMES ${ }^{1,2}$, Graça AFONSO ${ }^{1,2}$ \\ Acta Med Port 2020 Jan;33(1):7-14 - https://doi.org/10.20344/amp.12075
}

ABSTRACT

Introduction: Imaging tests are essential for diagnosis in the emergency context and convey clinical information that is essential to assess the appropriateness of the tests and improve their interpretation. Therefore, we aimed to analyze the imaging tests requested by the Emergency Department in a district hospital.

Material and Methods: We retrospectively analyzed computed tomography and ultrasound scans requested by the Emergency Department at the Centro Hospitalar Universitário do Algarve and considered the following variables: requested test, clinical information provided (complete/incomplete), appropriateness of the test (appropriate/inappropriate), outcome (presence/absence of relevant findings) and findings related to the clinical information (yes/no). Pearson's chi-squared and odds ratio association tests were used to evaluate the statistical association between the variables.

Results: Out of 1427 requests, only $219(15.3 \%)$ were considered to have complete clinical information. Nonetheless, 1075 (75.3\%) requests were considered appropriate. Relevant findings were present in about one-third $(n=453 ; 31.7 \%)$ and most of these findings were related to the clinical context $(n=410 ; 90.5 \%)$. There was a significant association between test appropriateness and the presence of relevant findings in the test $(p<0.001)$. The odds ratio of having a relevant finding was 5.0 times higher in the tests considered appropriate when compared with those classified as inappropriate $(\mathrm{Cl}=3.4-7.3 ; p<0.001)$.

Discussion: The fact that appropriate tests potentiate the probability of having a relevant finding emphasizes the importance of defining guidelines so that only the adequate tests are performed.

Conclusion: Creating guidelines should improve the appropriateness of imaging tests requested in the Emergency Department, yielding their result, with the consequent rationalization of the available resources.

Keywords: Diagnostic Imaging/statistics \& numerical data; Emergency Service, Hospital; Practice Patterns, Physicians; Radiology Department, Hospital; Unnecessary Procedures

\section{RESUMO}

Introdução: Os exames de imagem são essenciais para o diagnóstico em contexto de emergência, sendo a informação clínica determinante para verificar a sua adequação e melhorar a sua interpretação. O nosso objetivo compreendeu a análise dos exames de imagem requisitados pelo Departamento de Emergência num hospital distrital.

Material e Métodos: Realizámos uma análise retrospetiva das tomografias computorizadas e ecografias requeridas pelo Departamento de Emergência no Centro Hospitalar Universitário do Algarve considerando as seguintes variáveis: exame requisitado, informação clínica fornecida (completa/incompleta), adequação do exame (adequado/não adequado), resultado (presença/ausência de achados relevantes) e relação dos achados com contexto clínico (relacionados/não relacionados). A associação entre variáveis foi avaliada utilizando as análises qui-quadrado de Pearson e razão de possibilidades.

Resultados: Das 1427 requisições, apenas $219(15,3 \%)$ foram consideradas como contendo informação clínica completa. No entanto, $1075(75,3 \%)$ requisições foram consideradas adequadas. Cerca de um terço dos exames continha achados relevantes $(\mathrm{n}=$ $453 ; 31,7 \%$ ) e a maioria destes achados estavam relacionados com o contexto clínico $(n=410 ; 90,5 \%)$. Encontrámos associações significativas entre a adequação do pedido e presença de achados clínicos relevantes $(p<0,001)$. A razão de possibilidades de ter um achado relevante é 5,0 vezes maior nos pedidos adequados relativamente aos não adequados $(\mathrm{IC}=3,4-7,3 ; p<0,001)$.

Discussão: $O$ facto de os exames adequados potenciarem a probabilidade de existir um achado relevante enfatiza a importância da definição de diretrizes para que só os exames adequados sejam realizados.

Conclusão: A criação destas diretrizes deverá aumentar a adequação dos exames de imagem solicitados no Departamento de Emergência, otimizando o seu resultado, com a consequente racionalização dos recursos disponíveis.

Palavras-chave: Diagnóstico por Imagem/estatística e dados numéricos; Padrões de Prática Médica; Procedimentos Desnecessários; Serviço de Emergência; Serviço Hospitalar de Radiologia

\section{INTRODUCTION}

Imaging tests are very useful in current clinical practice allowing clinicians to obtain a diagnosis, to make assisted procedures or to establish a treatment plan. Imaging tests have been increasingly used worldwide in the last few

years, especially in the Emergency Department (ED). ${ }^{1-3}$

Despite the fact that imaging tests are indispensable nowadays, its increasing use can lead to an increase in the costs and length of patient stays in EDs and intensive

\footnotetext{
1. Serviço de Radiologia. Centro Hospitalar Universitário do Algarve. Faro e Portimão. Portugal.

2. Algarve Biomedical Center. Faro. Portugal.

3. Departamento de Ciências Biomédicas e Medicina. Universidade do Algarve. Faro. Portugal.

$\triangle$ Autor correspondente: Rute Martins. rutepaulomartins@gmail.com

Recebido: 18 de março de 2019 - Aceite: 27 de junho de 2019 | Copyright @ Ordem dos Médicos 2020
} 
care units. ${ }^{4-6}$ On the other hand, some imaging tests are, in fact, unnecessary to establish a diagnosis or to improve the patients' outcome and their benefits cannot outweigh the risks. ${ }^{4,7}$ For instance, computed tomography (CT) scans use high doses of radiation and repeated exposure increases the risk of cancer, especially in children. ${ }^{8,9}$ In addition to the radiation risks, some $\mathrm{CT}$ scans require injection of contrast that may lead to severe allergic reactions or post-contrast acute kidney injury. ${ }^{8}$

In order to increase the appropriateness of imaging test requests by clinicians and to prioritize the tests, the American College of Radiology (ACR) formulated appropriateness criteria. ${ }^{10}$ These criteria are evidence-based guidelines created to assist referring clinicians and other healthcare providers in making the best imaging or treatment decisions in specific clinical contexts. ${ }^{10,11}$ Although ACR guidelines are being used worldwide, a large number of unnecessary imaging tests are still requested by EDs. ${ }^{4,8}$ Considering the Portuguese reality, the National Health Directorate has been developing clinical practice guidelines since 2011 (Normas de Orientação Clínica) that provide crucial support tools to improve the quality of clinical practice, including imaging test appropriateness in some particular clinical contexts. ${ }^{12}$ In addition, the clinical information provided by the attending clinician at the time of the test request is critical to assess not only the appropriateness of the test but also to improve the interpretation of its result. Several studies have demonstrated that the availability of appropriate clinical information yielded more accurate radiological interpretations. ${ }^{13-17}$ However, this information is not always as detailed as desirable, and some radiology tests are even interpreted with no clinical information available. ${ }^{18}$

Our aim was to analyze imaging tests, i.e. computed tomography scans and ultrasound exams, by requested test, appropriateness of the requested test according to the clinical information provided, and the outcome of the test performed, that were requested to the Radiology Department by the Emergency, Urgent and Intensive Care Department (further referred to as Emergency Department [ED]) at the Centro Hospitalar Universitário do Algarve (CHUA).

\section{MATERIAL AND METHODS \\ Study design and setting}

This retrospective study was conducted at the Radiology Department of CHUA - Faro Unit, Portugal. This is a hospital with a polyvalent ED, which corresponds to the highest level of differentiation in Portugal. All CT scans and ultrasound exams requested to the Radiology Department between July 12 and July 31, 2018, were included in the study. Data on the imaging tests were collected retrospectively from the Radiology Department database using the RIS-Glintt ${ }^{\circledR}$ software (version 16 R1.01.06).

This study was approved by the CHUA's Ethics Committee and performed according to the Declaration of Helsinki.

\section{Data collection and variables}

Data were collected into an Excel database. The selected variables included: patient's entry date, gender, and age; source of the imaging test request, requested imaging test, clinical information provided by the clinician, test appropriateness, performed imaging test, causes of test cancelation (if applicable), relevant findings, and findings related to the clinical information.

The source of the requested test concerns the three units that belong to the ED: the Polyvalent Urgent Care Department (Serviço de Urgência Polivalente [SUP]), the Polyvalent Intensive Care Unit (Unidade de Cuidados Intensivos do Serviço de Urgência [UCIP]) and the Emergency Department Intermediate Care Unit (Unidade de Cuidados Intermédios do Serviço de Urgência [UCISU]). After admission at the ED, the SUP corresponds to the department where the patient is first observed, being afterward admitted or discharged according to the clinical situation. UCIP and UCISU are intensive care units harboring the critical patients coming from SUP or another hospital department.

The assessed clinical information was classified as complete, incomplete or missing. Complete was defined as clinical information provided with: (i) a brief history of the current disease or condition; (ii) relevant findings in the physical examination; (iii) laboratory tests (if applicable); and (iv) diagnostic hypotheses (at least one). If the clinical information lacked at least one of the previously mentioned criteria, it was defined as incomplete. If no clinical information was provided, the clinical information was classified as missing.

The test appropriateness was defined according to the ACR Appropriateness Criteria. ${ }^{19}$ These criteria were used to decide, according to the clinical information provided in the request, if an imaging test had an indication to be performed, or if it does not add any value to the clinical decision-making process in the emergency context. When possible, the Portuguese clinical practice guidelines (Normas de Orientação Clínica) were also assessed, although restricted by the few available clinical scenarios for test appropriateness.

Findings in the test report were considered as relevant if: i) the findings were directly related with the clinical information provided, or ii) the finding provided important clinical information that required the patient's follow-up in an ambulatory context (lung nodules, pancreatic cysts, other hepatic/kidney/adrenal/adnexal incidentalomas, etc.). All other situations were considered as non-relevant findings (e.g. lumbar degenerative disease, non-obstructive kidney stones, benign variant anatomy).

Findings related to the clinical information were defined as findings directly related to the information provided by the attending clinician in the imaging test request.

\section{Statistical analysis}

All analyses were conducted using the IBM SPSS Statistics ${ }^{\circledR}$ software (version 25). Continuous variables were summarized by the mean and standard deviation. Categorical variables were summarized by frequency and percentage in each group.

Pearson's chi-squared and odds ratio (OR) association 


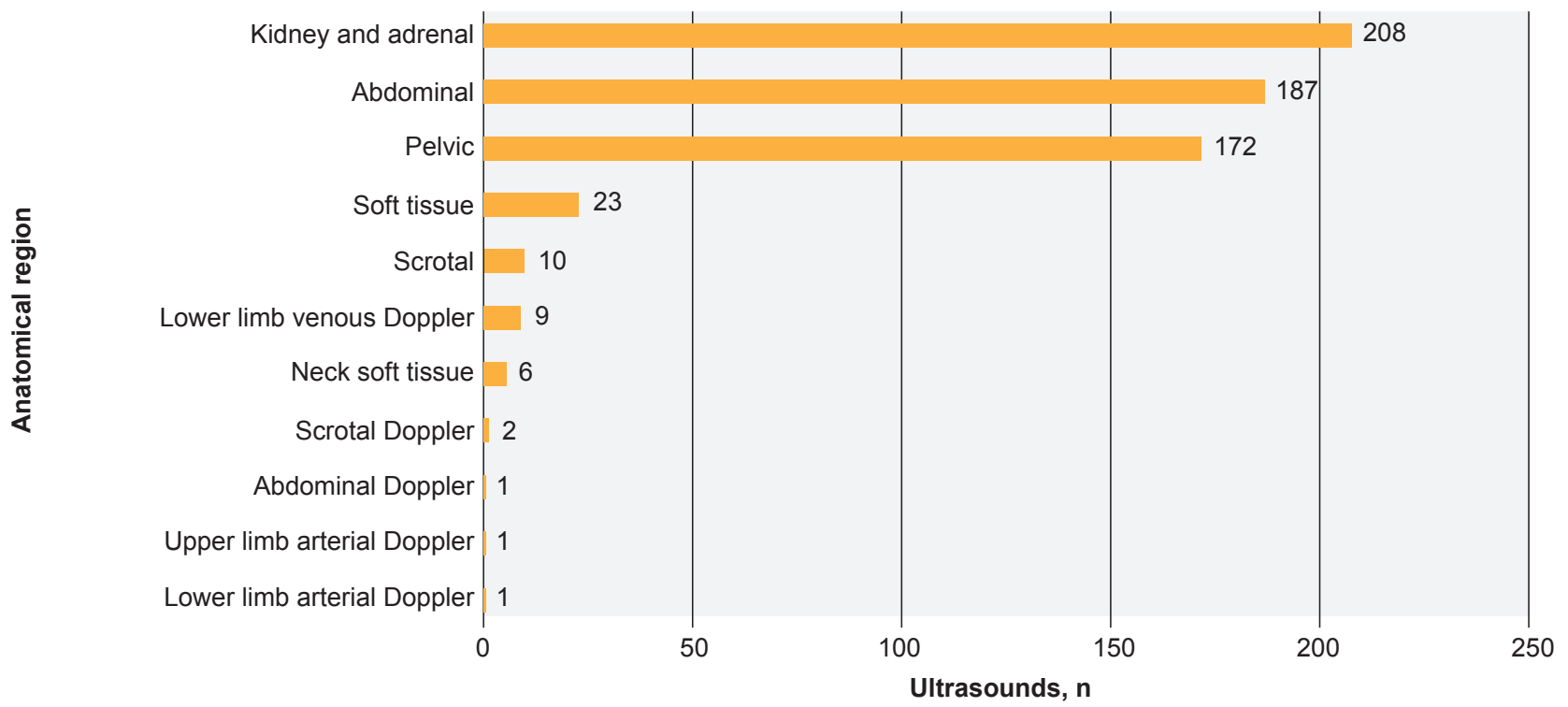

Figure 1 - Frequency distribution of the requested ultrasounds by anatomical region

(Mantel-Haenszel) tests were used to evaluate the statistical association between the variables test appropriateness and relevant findings. These analyses were performed considering the CTs and ultrasounds separately and together. The tests classified as inconclusive were excluded from the $\mathrm{OR}$ analyses. The association between the variables relevant findings and findings related to the clinical information was analyzed with the Pearson's chi-squared test, as the Mantel-Haenszel association analysis is not possible to perform for these variables. The statistical significance level was set at the $5 \%$ level.

\section{RESULTS}

\section{Patients' demographics}

A total of 1427 imaging tests concerning CT scans and ultrasound exams, requested by the SUP, UCIP, and UCISU, were included in the study. The requested tests had a patient's mean age of $55.7 \pm 23.3$ years old (mean \pm standard deviation) and the majority were from male patients $(n=799,56 \%)$. These demographic data are summarized in the Appendix 1 (Appendix 1: https://www.actamedicaportuguesa.com/revista/index.php/amp/article/ view/12075/Appendix_01.pdf).

\section{Test requests by the Emergency Department}

Regarding the origin of the imaging test requests, 1377 tests $(96.5 \%)$ were requested by the SUP, $37(2.6 \%)$ from the UCIP and $12(0.8 \%)$ from the UCISU.

Overall, 620 of the 1427 requested tests were ultrasounds $(43.4 \%)$. Fig. 1 shows the frequency of requested ultrasound tests by anatomical region, revealing that the most requested tests were kidney and adrenal $(14.6 \%)$, abdominal (13.1\%), and pelvic (12.1\%). The least requested ultrasounds were lower limb arterial Doppler, upper limb arterial Doppler, and abdominal Doppler (Fig. 1).

The distribution of requested CT scans is shown in Fig. 2.

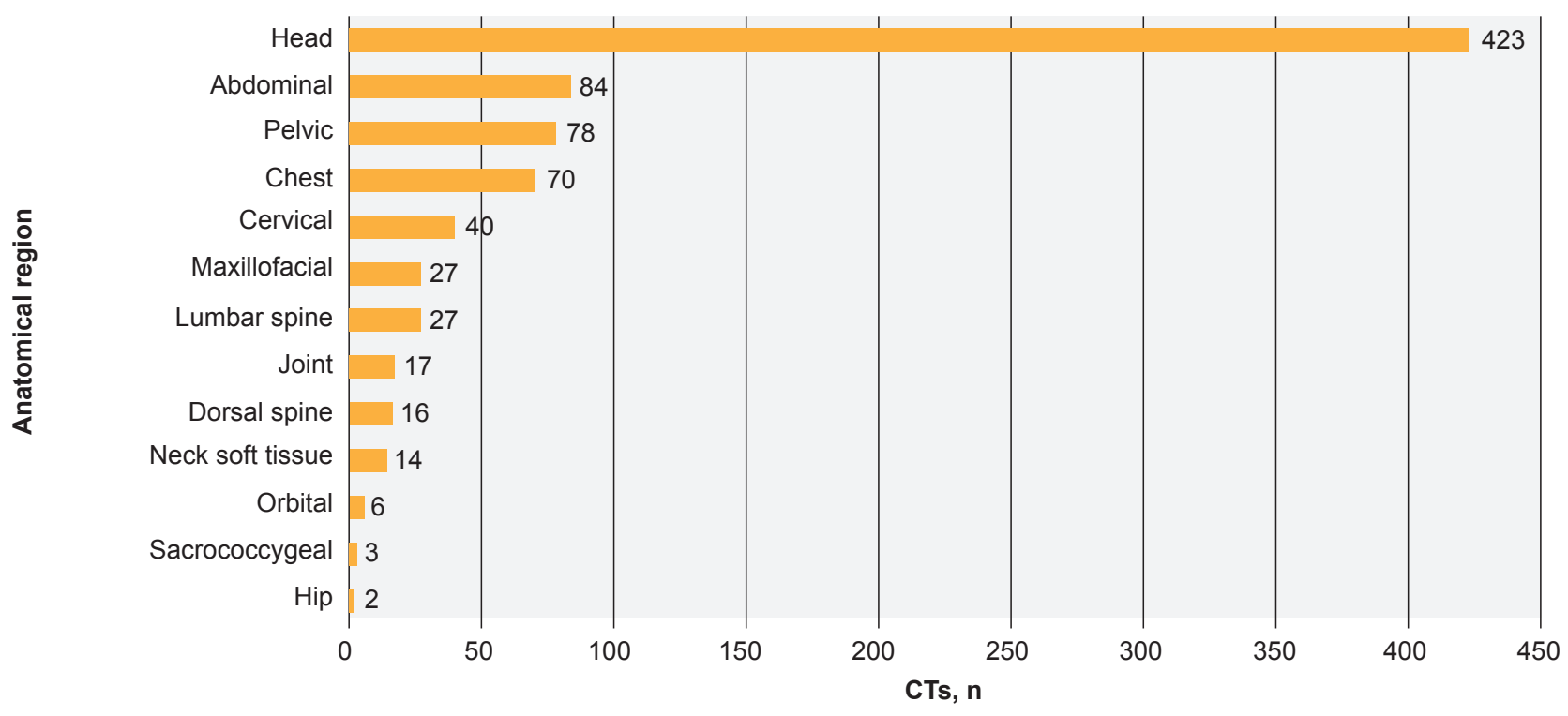

Figure 2 - Frequency distribution of the requested CT scans by anatomical region 


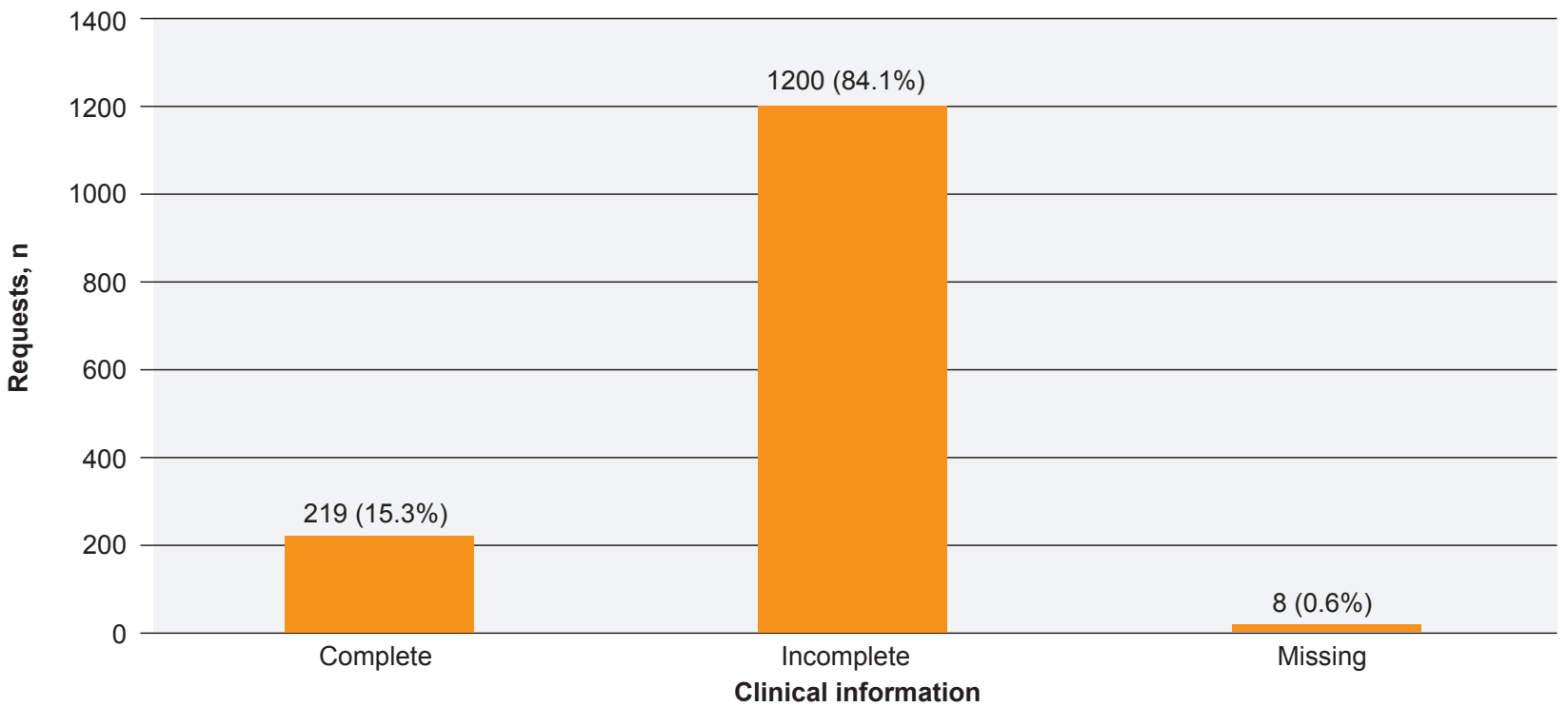

Figure 3 - Frequency distribution according to the classification of the clinical information provided by the clinician

From the total of 1427 imaging tests, 807 (56.6\%) were CT scans. Head CT was the leading requested test with $29.6 \%$ of the requests, followed by abdominal (5.9\%), pelvic $(5.5 \%)$ and chest CT. Hip was the least requested test with only $0.1 \%$ of the requests.

\section{Clinical information}

The classification of the clinical information provided by the attending clinicians when requesting an imaging test is presented in Fig. 3. Most of the requests had incomplete clinical information (84.1\%), while complete clinical information was provided in $15.3 \%$ of the requests.

\section{Test appropriateness}

Test appropriateness according to the clinical information is shown in Fig. 4. About $75.3 \%$ of the requests were considered appropriate regarding the clinical information supplied, while $23.8 \%$ were considered as inappropriate. Also, $0.9 \%$ of the requested tests either lacked (8 requests) or had insufficient clinical information (5 requests), not allowing their appropriateness to be checked.

\section{Canceled tests}

Considering all the requests analyzed, 1336 (93.6\%) correspond to performed tests, while 91 (6.4\%) were canceled. Causes of test cancelation are shown in Appendix 1 (Supplemental Fig. 1 in https://www.actamedicaportuguesa.com/revista/index.php/amp/article/view/12075/ Appendix_01.pdf). "Inappropriate request in emergency medicine context" and "patient discharged" were the main reasons for cancellation with 20 tests each. The minor reasons for test cancellation were: "patient missed information in Alert $^{\circledR}$ system" and "patient refused the test".

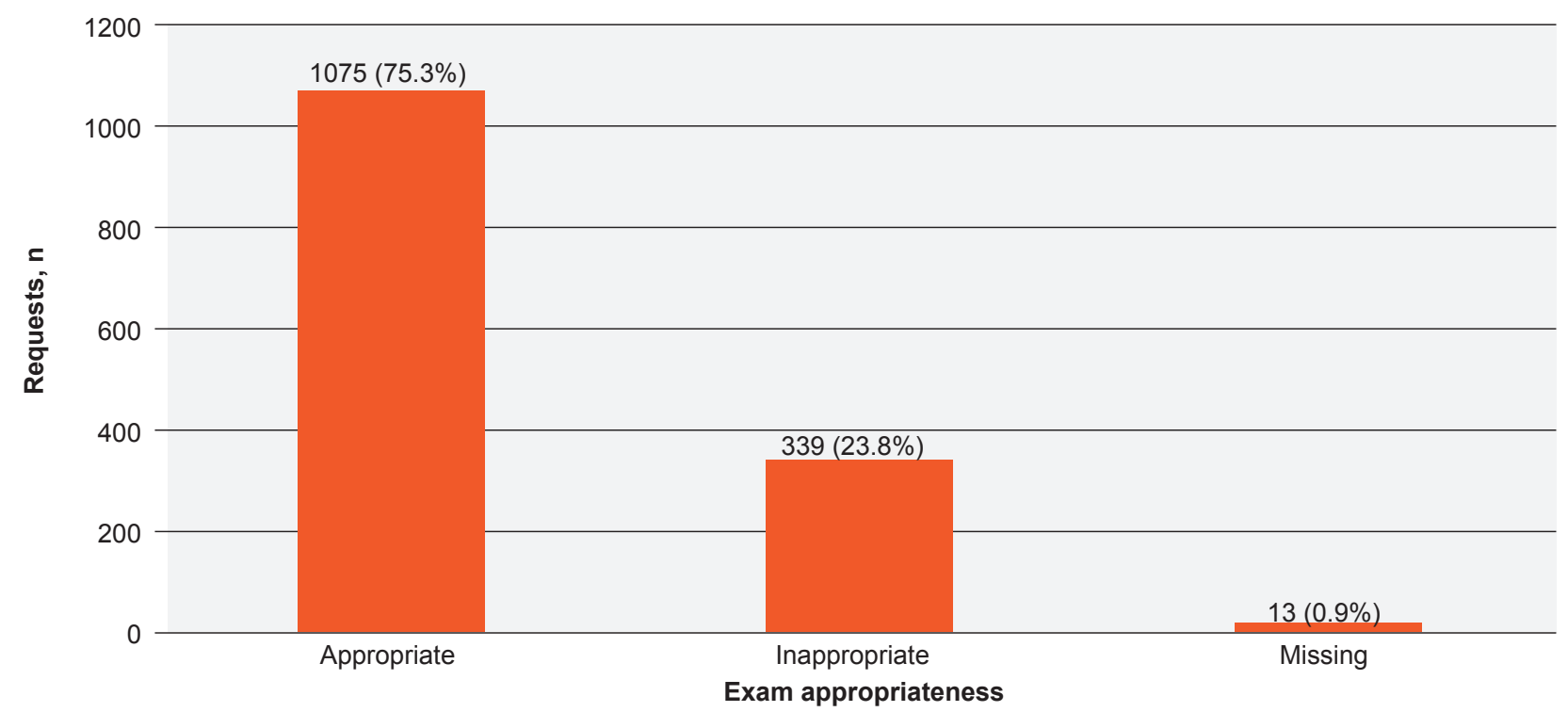

Figure 4 - Frequency distribution according to the classification of the test appropriateness. Missing data refers to requests that lacked or had insufficient clinical information to check its appropriateness. 


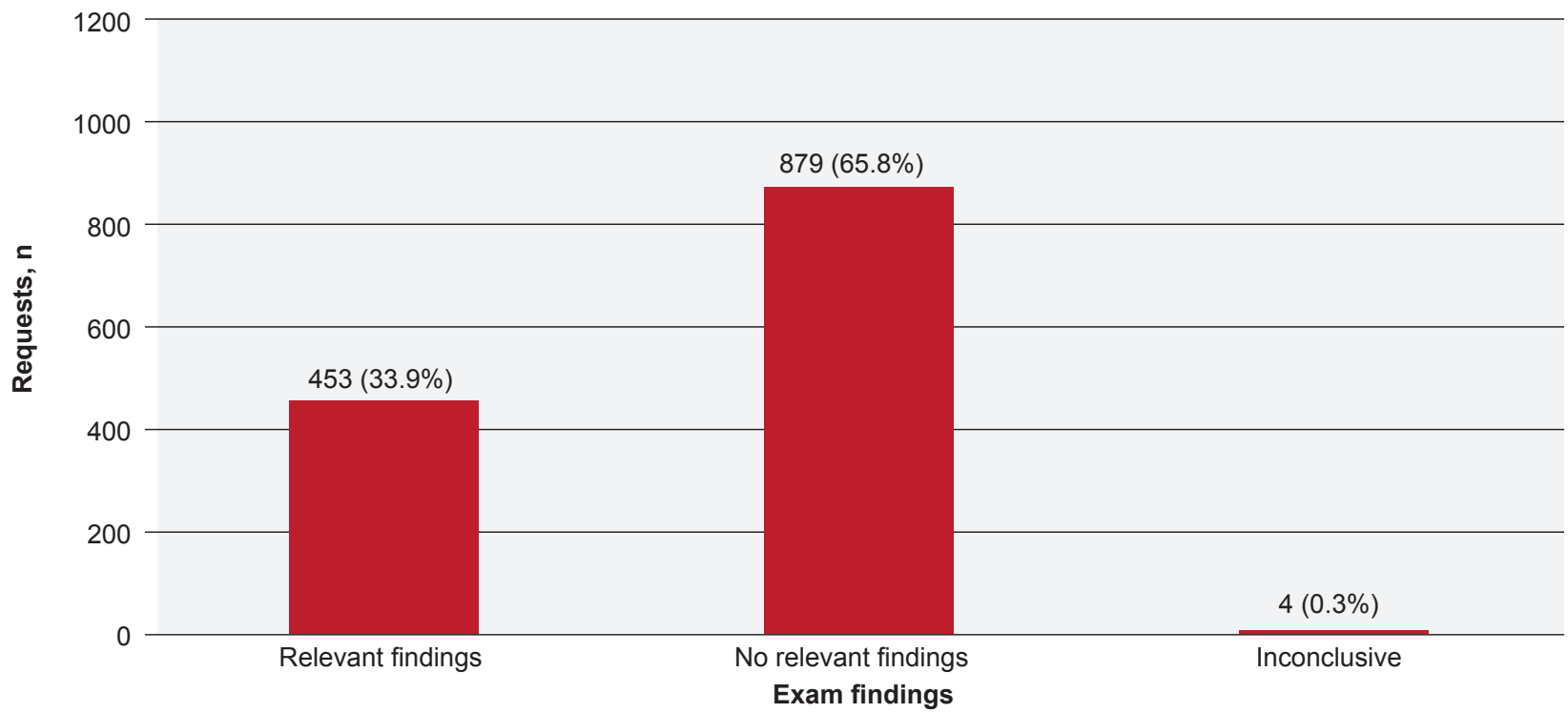

Figure 5 - Frequency distribution according to the classification of test findings in the performed tests

\section{Test findings}

Fig. 5 concerns the outcomes of the performed tests, specifically, whether the report reveals important findings or not. From the total of 1336 tests performed, relevant findings were present in $33.9 \%$, while $65.8 \%$ showed no relevant findings and $0.3 \%$ tests were considered inconclusive.

\section{Association between test appropriateness and relevant findings}

The frequency of tests with relevant findings by test appropriateness is shown in Table 1. From a total of 1336 performed tests, 1041 were considered to be appropriate according to the clinical information provided. Amongst the latter, $418(40.1 \%)$ tests have shown relevant findings in the corresponding reports. On the other hand, from a total of the 295 tests considered as inappropriate, $35(11.9 \%)$ were found to have relevant findings, whereas 259 (87.8\%) did not. Examples of relevant findings in tests considered as inappropriate are, for instance, the presence of lung parenchyma inflammatory infiltrates in a chest CT in a patient with a previously known pneumonia or nodular lesions in the spleen possibly corresponding to lymphoma in an abdominal TC performed in a patient with "shortness of breath with a one-week history of pain in the lower left limb" provided as clinical information.

There was a significant association between test appropriateness according to the clinical information and test with relevant findings $\left[\chi^{2}(2)=82.131, p<0.001\right]$. This significant association was also observed when concerning the TCs $\left[\chi^{2}(1)=21.979, p<0.001\right]$ and the ultrasounds separately $\left[\chi^{2}(2)=57.481, p<0.001\right]$.

The odds ratio of having a relevant finding was 5.0 times higher in the tests considered appropriate when compared with those classified as inappropriate $(\mathrm{OR}=5.0 ; \mathrm{Cl} 3.4-7.3$; $p<0.001)$. The OR considering the ultrasounds only was of $6.9(\mathrm{OR}=6.9 ; \mathrm{Cl} 4.0-12.0 ; p<0.001)$ and it was 3.3 for the CTs $(\mathrm{OR}=3.3 ; \mathrm{Cl} 2.0-5.5 ; p<0.001)$.

\section{Association between relevant findings and clinical con- text}

Out of the 35 tests regarded as inappropriate that have shown relevant findings, 26 tests had findings related to the clinical context while 9 tests did not.

From a total of 453 tests considered with relevant findings, $410(90.5 \%)$ findings were related to clinical context, whereas in 43 reports $(9.5 \%)$ these findings were not related with the clinical context. A statistically significant association was observed between relevant findings and findings related to clinical context groups with $\chi^{2}(4)=2214.78$, $p<0.001$.

\section{DISCUSSION}

The intention of this study was to provide an overview of the status of the radiology tests requested by an ED in a hospital with a polyvalent emergency department. In what concerns the source of tests requested, the SUP was the leading unit, with of $96.5 \%$ of the total tests analyzed. This was a rather expected result since, as a first encounter at

Table 1 - Cross-table between test appropriateness and test with relevant findings

\begin{tabular}{lcccc}
\hline & \multicolumn{3}{c}{ Relevant findings } & Total, $\mathrm{n}(\%)$ \\
\cline { 2 - 4 } Test appropriateness & Yes & No & Inconclusive & $1041(100)$ \\
\hline Yes, $\mathrm{n}(\%)$ & $418(40.1)$ & $620(59.6)$ & $3(0.3)$ & $295(100)$ \\
No, $\mathrm{n}(\%)$ & $35(11.9)$ & $259(87.8)$ & $1(0.3)$ & 1336 \\
Total, $\mathrm{n}$ & 453 & 879 & 4 & \\
\hline
\end{tabular}


the ED admission, the SUP is expected to consume most of the requested tests when compared to UCIP or the UCISU, due to the frequent need of imaging tests to confirm a diagnosis or establish a treatment plan. ${ }^{1-3}$

The greatest proportion of requested ultrasounds was kidney and adrenal, abdominal and pelvic. Generally, these three tests are requested to approach the differential diagnoses of urinary tract obstructions, acute cholecystitis and acute appendicitis, respectively. These are, in fact, the most frequent diagnoses that this imaging technique may reveal in the emergency context. ${ }^{20}$ The less frequent ultrasound tests requested were lower limb arterial Doppler and upper limb arterial Doppler. These two tests are useful to evaluate ischemia, which is an unusual cause of a visit to the ED. ${ }^{21,22}$

Head traumas, acute delirium and strokes are common causes for visiting an ED, ${ }^{23-25}$ as indicated in our results, where the head CT scan was the most frequent test requested. This proportion may also be the result of the guidelines implemented at our hospital, which are aimed at excluding brain injuries even in minor head traumas, therefore avoiding subsequent morbidity, especially in elderly taking antiplatelet agents and anticoagulants. In cases of acute delirium, the CT scan should only be performed if there is at least one of the following: history of falls, head injury, patient on anticoagulation, presence of focal neurological signs or evidence of raised intracranial pressure. ${ }^{26}$ Head CT is also frequently requested in order to exclude brain injuries in patients with a suspected stroke to evaluate brain injuries and to establish a treatment plan. ${ }^{27-29}$ Another explanation for the amount of head CT requests could be the limited access to magnetic resonance imaging (MRI) in our hospital and the time needed to perform these tests, as CT scans take less time than MRI scans. ${ }^{18,30}$

The second and third most requested CT scans were abdominal and pelvic CTs. These imaging tests are generally performed together to evaluate patients that present with nonspecific abdominal pain, with or without fever. The most frequent conditions that present with acute abdominal pain in the ED are acute appendicitis, acute cholecystitis, small-bowel obstruction, pancreatitis, renal colic, perforated peptic ulcer, cancer, and diverticulitis. ${ }^{31,32}$ Abdominal and pelvic CT scans are also determinant when an ultrasound is inconclusive or it is difficult to perform due to the body habitus of the patient or if the patient is uncooperative. ${ }^{33}$

Some studies have shown that up to $30 \%$ of imaging tests are ordered primarily for defensive purposes. ${ }^{34}$ Albeit the difficulty to quantify, most observers agree that it represents a contribution of about one-quarter of total imaging costs. ${ }^{35}$ So, although it was not an objective of this study to evaluate directly the overuse of imaging tests, it is meaningful to keep in mind that this overuse its frequently associated with defensive medical practices, namely, in the ED. ${ }^{34,35}$

The analysis of clinical information has shown that a significant proportion of requests had incomplete clinical information. Attending clinicians at the ED who request an imaging test frequently experience several difficulties. Some patients are uncooperative, sometimes little information is described in the clinical records and the laboratory results may take longer than expected. All these reasons together make the task of gathering complete clinical information and of narrowing down the possible diagnostic hypotheses far more difficult.

Consequently, often the imaging test request is done without including enough clinical information, which obviously poses a difficult task for the radiologist. In these cases, the radiologist often needs to search for further information by other means or approach the attending clinician to further understand the clinical context of a given patient and to ascertain whether the test(s) requested is, in fact, useful. This represents a significant proportion of time, with consequences for both the patients who require imaging tests that rely on the radiologist's execution/interpretation/ support and also for the organization of the Radiology Department in the emergency context.

Interestingly, although most requests had incomplete clinical information, $75.3 \%$ of the total was considered as appropriately requested in the emergency context according to the ACR criteria. This apparent discrepancy between the percentage of tests with complete clinical information and the tests considered appropriate may be explained in several ways. First, a significant proportion of the requests just provided a small amount of information (e.g. "appendicitis?", "left renal colic, to exclude obstruction", "head trauma in an elderly patient", etc.) but that was enough for the test to be considered appropriate. Second, as previously mentioned, further information is often requested by the radiologist to further understand the clinical context of a given patient. Finally, when in doubt, in a particular clinical context, if it was felt that performing the test was considered to have any benefit in the clinical management of a patient, the test requested was performed.

Only about one-third of the tests performed were considered to have relevant findings. The statistical analysis showed a significant association between test appropriateness and the presence of relevant findings. A test that was considered appropriate was shown to potentiate about 5 times more the probability of having a relevant finding. This outcome was even more evident for the ultrasound tests, in which the appropriateness increases the odds of having a relevant finding by a factor of 7 . These results highlight the importance of establishing guidelines so that only the adequate tests are performed, yielding their result and rationalizing the (scarce) resources available.

Most of the relevant findings found in the analyzed tests were related to the clinical information supplied, while only in $9.5 \%$ the findings there was no apparent relationship with the clinical information provided. A possible explanation for these cases could be due to the fact that the scarce clinical information did not allow the establishment of a link between clinical scenario and the test findings. One of the limitations of our study concerns the fact that it was performed at a single hospital. To our knowledge, no other studies are available concerning the clinical information and appropriateness 
of imaging tests in Portuguese hospitals. We believe, since Emergency Departments work in a similar way throughout the country, that it is likely that the results would be comparable to other hospitals. As some tests were canceled, selection bias should also be mentioned as a limitation of this study, since the analyses that rely on the outcome of the test were not performed in these cases. Other limitations include its retrospective nature with all the associated pitfalls, the short timeframe and the fact that our population suffers significant changes during the summer period. The fact that the appropriateness of the requests was based (although not solely) on the ACR Criteria can also be considered a limitation. The subjectivity regarding the interpretations of the relevant findings may be considered as another limitation of this study, but it was (at least partially) overcome by discussing the cases in doubt (usually abdominal or pelvic CTs) amongst the Radiology specialists involved in this study. Moreover, one significant limitation of this study also relates to the relevant findings, as only the positive results were considered as such. The complexity and diversity of requests and clinical scenarios analyzed, together with the difficult task to interpret incomplete clinical information in the vast majority of the requests, made it impossible to consider a negative result of the test as relevant.

\section{CONCLUSION}

This study discloses that clinical information has a key importance when requesting an imaging test, supported by the fact that $75.3 \%$ of the tests were considered appropriate in a total of $84.1 \%$ requests without complete clinical information. This implies that a significant amount of time is taken up with the analysis of the appropriateness of a given test. This reinforces previous studies, revealing that the communication between doctors, that in this case takes the form of clinical information, should be improved.

Most importantly, the main conclusion is that appropriate tests potentiate five times the probability of having a relevant finding, therefore emphasizing the importance of defining guidelines so that only the adequate tests are performed. An upgrade in the quality of the clinical information together with the strict implementation of guidelines based on the ACR Appropriateness Criteria would most certainly improve the appropriateness of the imaging tests requested in the ED, yielding their result, with the consequent rationalization of the available resources. To achieve this, regular meetings between the Radiology and Emergency Departments have already begun to analyze the feasibility of this implementation.

\section{PROTECTION OF HUMANS AND ANIMALS}

The authors declare that the procedures were followed according to the regulations established by the Clinical Research and Ethics Committee and to the Helsinki Declaration of the World Medical Association.

\section{DATA CONFIDENTIALITY}

The authors declare having followed the protocols in use at their working center regarding patients' data publication.

\section{CONFLICT OF INTEREST}

No conflict of interest has been declared by any author.

\section{FUNDING SOURCES}

No financial support was received by any author.

\section{REFERENCES}

1. Kocher KE, Meurer WJ, Fazel R, Scott PA, Krumholz HM, Nallamothu BK. National trends in use of computed tomography in the emergency department. Ann Emerg Med. 2011;58:452-62.

2. Raja AS, Mortele KJ, Hanson R, Sodickson AD, Zane R, Khorasani R. Abdominal imaging utilization in the emergency department: trends over two decades. Int J Emerg Med. 2011;4:2-7.

3. Rosenkrantz AB, Hanna TN, Babb JS, Duszak R. Changes in emergency department imaging: perspectives from national patient surveys over two decades. J Am Coll Radiol. 2017;14:1282-90.

4. Raja AS, Ip IK, Sodickson AD, Walls RM, Seltzer SE, Kosowsky JM, et al. Radiology utilization in the emergency department: trends of the past 2 decades. Am J Roentgenol. 2014;203:355-60.

5. Kocher KE, Meurer WJ, Desmond JS, Nallamothu BK. Effect of testing and treatment on emergency department length of stay using a national database. Acad Emerg Med. 2012;19:525-34.

6. Pines JM. Trends in the rates of radiography use and important diagnoses in emergency department patients with abdominal pain. Med Care. 2009;47:782-6.

7. Yoon P, Steiner I, Reinhardt G. Analysis of factors influencing length of stay in the emergency department. J Emerg Med. 2003;5:155-61.

8. Baloescu C. Diagnostic imaging in emergency medicine: how much is too much? Ann Emerg Med. 2018;72:637-43.

9. Brenner DJ, Hall EJ. Computed tomography - an increasing source of radiation exposure. N Engl J Med. 2007;357:2277-84.

10. Cascade PN. Setting appropriateness guidelines for radiology. Radiology. 1994;192:50A-4.

11. Cascade PN, Bryan RN, Hattery RR. The American College of Radiology. ACR Appropriateness Criteria project. Radiology. 2000;214:3-46.

12. Normas e Circulares Normativas da Direcção Geral da Saúde [Homepage]. [accessed 2019 May 13]. Available from: https://www.dgs. $\mathrm{pt} / \mathrm{directrizes-da-dgs/normas-e-circulares-normativas.aspx.}$

13. Loy CT, Irwig L. Accuracy of diagnostic tests read with and without clinical information. JAMA. 2004;292:1602.

14. Aideyan UO, Berbaum K, Smith WL. Influence of prior radiologic information on the interpretation of radiographic examinations. Acad Radiol. 1995;2:205-8.

15. Doubilet P, Herman P. Interpretation of radiographs: effect of clinical history. Am J Roentgenol. 1981;137:1055-58.

16. Baek SE, Kim MJ, Kim EK, Youk JH, Lee HJ, Son EJ. Effect of clinical information on diagnostic performance in breast sonography. J Ultrasound Med. 2009;28:1349-56.

17. McNeil BJ, Hanley JA, Funkenstein HH, Wallman J. Paired receiver operating characteristic curves and the effect of history on radiographic interpretation. CT of the head as a case study. Radiology. 1983;149:757.

18. Hanna TN, Rohatgi S, Shekhani HN, Dave IA, Johnson JO. Clinical information available during emergency department imaging order entry and radiologist interpretation. Emerg Radiol. 2017;24:361-67.

19. American College of Radiology ACR Appropriateness Criteria ${ }^{\circledR}$ [Homepage]. [accessed 2019 Mar 7]. Available from:t https://acsearch. acr.org/list.

20. Van Randen A, Laméris W, van Es HW, van Heesewijk HP, van Ramshorst B, Ten Hove W, et al. A comparison of the accuracy of ultrasound and computed tomography in common diagnoses causing acute abdominal pain. Eur Radiol. 2011;21:1535-45.

21. Expert Panel on Vascular Imaging:, Weiss CR, Azene EM, Majdalany 
BS, AbuRahma AF, Collins JD, et al. ACR Appropriateness Criteria ${ }^{\circledR}$ Sudden Onset of Cold, Painful Leg. J Am Coll Radiol. 2017;14:S307-13.

22. Santistevan JR. Acute limb ischemia: an emergency medicine approach. Emerg Med Clin North Am. 2017;35:889-909.

23. Bruns J, Hauser WA. The epidemiology of traumatic brain injury: a review. Epilepsia. 2003;44:2-10.

24. Tamune $\mathrm{H}$, Yasugi $\mathrm{D}$. How can we identify patients with delirium in the emergency department?: A review of available screening and diagnostic tools. Am J Emerg Med. 2017;35:1332-4.

25. Feigin VL, Lawes CM, Bennett DA, Anderson CS. Stroke epidemiology: a review of population-based studies of incidence, prevalence, and case-fatality in the late 20th century. Lancet Neurol. 2003;2:43-53.

26. Vijayakrishnan R, Ramasubramanian A, Dhand S. Utility of head CT scan for acute inpatient delirium. Hosp Top. 2015;93:9-12.

27. Expert Panel on Neurologic Imaging:, Salmela MB, Mortazavi S, Jagadeesan BD, Broderick DF, Burns J, et al. ACR Appropriateness Criteria $^{\circledR}$ Cerebrovascular Disease. J Am Coll Radiol. 2017;14:S34-61.

28. Campbell BC, Mitchell PJ, Kleinig TJ, Dewey HM, Churilov L, Yassi N et al. Endovascular therapy for ischemic stroke with perfusion-imaging selection. N Engl J Med. 2015;372:1009-18.

29. Berkhemer OA, Fransen PS, Beumer D, van den Berg LA, Lingsma
HF, Yoo AJ, et al. A randomized trial of intraarterial treatment for acute ischemic stroke. N Engl J Med. 2015;372:11-20.

30. Earnest $F$, Baker HL, Kispert DB, Laws ER. Magnetic resonance imaging vs. computed tomography: advantages and disadvantages. Clin Neurosurg. 1985;32:540-73.

31. Mindelzun RE, Jeffrey RB. Unenhanced helical CT for evaluating acute abdominal pain: a little more cost, a lot more information. Radiology. 1997;205:43-5

32. Expert Panel on Gastrointestinal Imaging:, Scheirey $C D$, Fowler KJ, Therrien JA, Kim DH, Al-Refaie WB, et al. ACR Appropriateness Criteria ${ }^{\circledR}$ Acute Nonlocalized Abdominal Pain. J Am Coll Radiol. 2018;15:S21731.

33. Yarmish GM, Smith MP, Rosen MP, Baker ME, Blake MA, Cash BD, et al. ACR appropriateness criteria right upper quadrant pain. J Am Coll Radiol. 2014;11:316-22.

34. Ortashi O, Virdee J, Hassan R, Mutrynowski T, Abu-Zidan F. The practice of defensive medicine among hospital doctors in the United Kingdom. BMC Med Ethics. 2013;14:42.

35. Hendee WR, Becker GJ, Borgstede JP, Bosma J, Casarella WJ Erickson BA, et al. Addressing overutilization in medical imaging. Radiology. 2010;257:240-5. 